The Role of Best Friends in Educational Identity Formation in Adolescence Lotte van Doeselaar $^{\mathrm{a}, *}$, Wim Meeus ${ }^{\mathrm{a}, \mathrm{c}}$, Hans M. Koot ${ }^{\mathrm{b}}$, and Susan Branje ${ }^{\mathrm{a}}$

${ }^{\text {a }}$ Research Centre Adolescent Development, Utrecht University, P.O. Box 80140, 3508 TC, Utrecht, the Netherlands

${ }^{\mathrm{b}}$ Department of Developmental Psychology, VU University, Van der Boechorststraat 1, 1081 BT Amsterdam, the Netherlands

${ }^{\mathrm{c}}$ Department of Developmental Psychology, Tilburg University, P.O. Box 90153, 5000 LE Tilburg, the Netherlands

* Corresponding author.

E-mail address: lottevandoeselaar@gmail.com

\title{
Acknowledgements
}

Data of the RADAR study were used. RADAR has been financially supported by main grants from the Netherlands Organisation for Scientific Research (GB-MAGW 480-03-005, GB-MAGW 480-08-006), and Stichting Achmea Slachtoffer en Samenleving (SASS), a grant from the Netherlands Organisation for Scientific Research to the Consortium Individual Development (CID; 024.001.003), and various other grants from the Netherlands Organisation for Scientific Research, the VU University Amsterdam, and Utrecht University.

This is the final author version (before journal's typesetting and copyediting) of the following paper: Van Doeselaar, L., Meeus, W., Koot, H. M., \& Branje, S. (2016). The role of best friends in educational identity formation in adolescence. Journal of Adolescence, 47, 28-37. doi:10.1016/j.jrp.2018.12.002 


\begin{abstract}
This 4-year longitudinal study examined over-time associations between adolescents' educational identity, perceived best friends' balanced relatedness, and best friends' educational identity. Adolescents $\left(N=464, M_{\mathrm{age}}=14.0\right.$ years at baseline, $56.0 \%$ males, living in the Netherlands) and their self-nominated best friends reported on their educational commitment, in-depth exploration, and reconsideration. Target adolescents also reported on the level of balanced relatedness provided by their best friend. Crosslagged panel models showed that balanced relatedness significantly predicted adolescents' reconsideration, and was predicted by in-depth exploration and, in an inconsistent pattern, by commitment. Best friends' educational identity did not positively predict adolescents' educational identity. Perceiving a best friend as high on balanced relatedness seems to reduce adolescents' problematic educational reconsideration, while, in turn, adaptive educational identity processes might foster balanced relatedness.
\end{abstract}

Keywords: educational identity, balanced relatedness, friend, adolescence, longitudinal. 
The Role of Best Friends in Educational Identity Formation in Adolescence

One of the main developmental tasks adolescents in Western societies face is the formation of a coherent sense of identity (Baumeister \& Muraven, 1996). An important domain in which adolescents construct their identity is education. Adolescents often have to choose schools, specific educational levels or tracks, and curricula. These choices not only affect their future vocational pathways, but also their interests and social position. Adolescents' friendships are thought to be related to this development of educational identity. During adolescence, friends show increasing respect for each other's needs and opinions (Shulman \& Knafo, 1997). These developments in adolescent educational identity and friendships might positively influence each other (McLean \& Jennings, 2012). Erikson (1968) already stated that identity is constructed within social interaction, and that a coherent identity is necessary to develop intimate friendships. Current cross-sectional studies support this interdependence between the developmental domains of identity and friendships (Doumen, et al., 2012; Johnson, 2012). However, longitudinal studies on the links between friendship and identity formation are rare (cf. Dumas, 2011; Reis \& Youniss, 2004). The present longitudinal study examined whether adolescents' educational identity is associated over time with their perception of the level of balanced relatedness provided by their best friend and with their best friend's educational identity.

\section{Identity Formation}

According to the Meeus-Crocetti model, which builds on Marcia's (1966) identity status paradigm, identity develops in a continuous interplay between making commitments, exploring commitments in-depth, and reconsidering commitments (Crocetti, Rubini, \& Meeus, 2008; Meeus, Van de Schoot, Keijsers, Schwartz, \& 
Branje, 2010). Commitment refers to making firm choices with regard to various domains and the self-confidence derived from these choices. In-depth exploration represents the extent to which present commitments are actively explored. It involves searching for information about these commitments, reflecting on one's choices, and discussing them with others. Finally, reconsideration of commitment refers to the willingness to discard one's present commitments and to search for alternative commitments. Commitment and in-depth exploration are generally thought to be adaptive processes, whereas reconsideration is thought to reflect the crisis-like aspect of identity formation (Crocetti, Rubini, \& Meeus, 2008).

Adolescents' educational identity development is expected to be triggered by several institutionalized moments of choice (Kalakoski \& Nurmi, 1998), such as choices regarding educational tracks or specific curricula during secondary education, and the choice for a major when entering tertiary education. The educational system expects adolescents to explore and to be committed to their educational choices. However, some adolescents might doubt whether their educational choices fit their needs. This could result in lower educational commitment and increased reconsideration, and might worsen their psychological well-being, academic adjustment, and later work identity (Branje, Laninga-Wijnen, Yu, \& Meeus, 2014; Luyckx, Soenens, Goossens, \& Vansteenkiste, 2007; Meeus, Iedema, Helsen, \& Vollebergh, 1999). Therefore, it is important to examine factors that relate to interindividual differences in adolescents' educational identity.

Interindividual differences in identity partly result from the interpersonal contexts in which identity is developed (Bosma \& Kunnen, 2001; Erikson, 1968). Intimate friendships are thought to form a safe interpersonal context for adolescents' 
identity development (McLean \& Jennings, 2012). By talking to friends about lived experiences, adolescents are thought to be able to integrate these experiences within their identity (McLean \& Pasupathi, 2010). It is theorized that during this process friends provide support and feedback, which might influence adolescents' identity formation (Kerpelman, Pittman, \& Lamke, 1997; Weeks \& Pasupathi, 2010).

\section{Friends' Balanced Relatedness}

During adolescence, individuality becomes more and more accepted within friendships (Selfhout, Branje, \& Meeus, 2009). Adolescents increasingly accept the opinions and ideas of their friend, even when they differ from their own. This characteristic of an intimate friendship is referred to as balanced relatedness (Shulman \& Knafo, 1997). Specifically this aspect of adolescent friendships might be associated with identity development, because it encompasses the acceptance within the friendship of the individual as an autonomous, independent individual who has own ideas and needs. Friends who are perceived as higher on balanced relatedness might form a safer environment for educational identity formation, because adolescents expect it to be likely that this friend will tolerate their view (Thorne \& Shapiro, 2011). Moreover, adolescents might feel supported in expressing personal views and in exploring and making their own educational choices. Findings from an earlier study indicated that peer groups open to and supportive of adolescents' opinions stimulate adolescents' general identity by relatively increasing in-depth exploration, but not commitment (Dumas, 2011). Although this prior study focused on the actual degree of balanced relatedness, adolescents' perceptions of balanced relatedness might have a stronger influence on their identity (Ryan, 2010). 
In turn, adolescents' identity might affect the perceived level of balanced relatedness provided by their friend. The formation of a coherent identity is thought to stimulate the development of intimate friendships, characterized by a high level of balanced relatedness, because there is less fear to lose the self in the friendship (Erikson, 1963). Adolescents who have constructed a relatively stable identity might feel more secure when expressing their views and be less likely to perceive their friend's reactions as confronting (Bauminger, Finzi-Dottan, Chason, \& Har-Even, 2008). Therefore, adolescents with a more stable identity might experience an increase in the degree of perceived balanced relatedness provided by their friend. Our study examined whether the level of perceived balanced relatedness provided by best friends is reciprocally positively related over time to adolescents' educational identity.

\section{Friends' Identity}

Adolescents and their friends are facing the same developmental task of constructing their identity. Identity control theory suggests that adolescents' identity is influenced by the identity of their friend (Kerpelman et al., 1997). When friends narrate about their experiences they provide self-relevant feedback to each other on their identity choices. We suggest that this self-relevant feedback might contain information on how one should develop an educational identity, such as "you should be committed to your educational choice". This way, highly committed adolescents might stimulate their friend to commit as well. Identity control theory states that when one's identity is not in line with the feedback received from friends, adolescents will adjust their identity to restore the balance (Kerpelman et al., 1997). Consequently, the development of identity of both the adolescent and best friend will be shaped, and as a result, will become more similar over time. 
In line with this perspective, friends were found to be more often in a similar state of general and domain-specific identity than random pairs (Akers, Jones, \& Coyl, 1998). Specifically, adolescents who had low levels of both educational exploration and commitment were more similar in this respect to their friend than random pairs. However, adolescents who scored high on either educational exploration, educational commitment, or both, were not more equal to their friends' educational identity than random pairs. In another study, adolescents' peer group members' general commitment, but not their exploration, was found to play a role in adolescents' general identity over time (Dumas, 2011). Although these studies suggest that adolescents' identity is linked to their friends' identity, more research is needed on the over-time associations between friends' educational identities. Therefore, we examined whether adolescents' and their best friends' educational identities are positively associated with each other over time.

\section{Stability of Friendship}

Although friendships are increasingly stable across adolescence (Branje, Frijns, Finkenauer, Engels, \& Meeus, 2007), there are quite some adolescents that change their best friends over the course of time. It is therefore important to distinguish the over-time influences that friends might have on each other from potential selection effects (Brechwald \& Prinstein, 2011). For example, adolescents with a strong educational identity might prefer a new best friend who provides a higher level of balanced relatedness. Furthermore, when adolescents end their friendship it is likely that the perceived balanced relatedness and educational identity of this friend have less influence on the adolescent's educational identity. To disentangle the hypothesized influence effects from these distorting factors, we differentiated between stable and unstable friendships. 


\section{Present Study}

In the present study, we examined whether adolescents' perceptions of the balanced relatedness provided by their best friends were reciprocally positively associated with adolescents' educational identity over time. Moreover, we examined whether adolescents' and best friends' educational commitment, in-depth exploration, and reconsideration were positively associated with each other over time.

\section{Method}

\section{Participants}

Participants were adolescents and their self-nominated best friends participating in the younger cohort of the longitudinal project 'Research on Adolescent Development and Relationships' (RADAR; van Lier, Frijns, Neumann, den Exter Blokland, Koot, \& Meeus, 2008). RADAR is an ongoing Dutch population-based cohort study. In the total RADAR young cohort, 497 adolescents participated in six annual waves from 2006 to 2011. As the first wave did not contain information on identity, we used data from the second to the sixth wave $(N=486)$, in this paper referred to as T1 to T5. Because friendships are the focus of the present study, adolescents who never brought a best friend in any of the waves $(n=22)$ were excluded from the analyses. Chi-square tests and a $t$-test showed that these adolescents did not differ from the other adolescents $(n=$ 464) on sex, socioeconomic status (SES), ethnicity, or age ( $p \mathrm{~s} \geq .122$ ). A series of MANOVAs showed no differences in any of the identity dimensions across the waves $(p s \geq .097)$.

Adolescents in the selected sample (56.0\% males) had a mean age of 14.0 years $(S D=0.45)$ at $\mathrm{T} 1$. Adolescents mainly identified themselves as Dutch $(95.7 \%)$ and lived in families with a medium or high SES (90.1\%). Of these adolescents, $90.7 \%$ had 
a participating best friend at T1 $\left(56.4 \%\right.$ males, $M_{\text {age }}=14.1$ years, $S D=0.78,93.1 \%$ identified themselves as Dutch), and $65.5 \%$ had a participating best friend at every wave. Friendships were moderately stable: across waves, between $61.6 \%$ and $69.8 \%$ brought the same friend in two adjacent waves. Furthermore, $34.9 \%$ of the adolescents brought the same best friend at all five waves. A series of chi-square tests and $t$-tests showed that adolescents within friendships which were stable across all waves did not differ from adolescents within unstable friendships on sex, age, ethnicity, or SES, best friends' sex, age, or ethnicity or perceived balanced relatedness across the waves ( $p \mathrm{~s} \geq$ .058). A series of MANOVAs showed that only at T5 best friends in stable and unstable friendships differed on the educational identity processes, $F(3,328)=3.05, p=.029$, $\eta_{p}^{2}=.03$. At T5 best friends' educational commitment in unstable friendships was lower $(M=17.61, S D=3.95)$, compared to stable friendships $(M=18.96, S D=4.30)$, $F(1,330)=8.91, p=.003, \eta_{p}^{2}=.03$. This difference was small and only occurring at one time point ( $p$ s at other time points $\geq .354$ ), and was not expected to distort the results. Adolescents' identity processes did not differ between stable and unstable friendships across the waves ( $p \mathrm{~s} \geq .103)$.

Attrition rate was relatively low. Of the adolescents in the selected sample, $96.8 \%, 94.4 \%, 92.5 \%, 89.2 \%$, and $88.8 \%$ participated in the five subsequent waves, respectively. Chi-square tests showed that drop-outs $(n=52)$ did not differ from adolescents still participating at T5 $(n=412)$ on sex or SES $(p s \geq .056)$. Furthermore, a $t$-test showed no differences in balanced relatedness, and two MANOVAs showed no differences in adolescents' and best friends' identity processes at T1 ( $p$ s $\geq .063)$. However, adolescents participating at T5 identified themselves more often as Dutch $(96.6 \%)$ than adolescents who dropped out during the course of the study $(88.5 \%), \chi^{2}(1$, 
$463)=7.39, p=.007, \varphi=.13$. Furthermore, drop-outs were somewhat older $\left(M_{\text {age }}=\right.$ 14.2 years at $\mathrm{T} 1, S D=0.54)$ than participating adolescents $\left(M_{\mathrm{age}}=14.0\right.$ years at $\mathrm{T} 1, S D$ $=0.44), t(60)=2.07, p=.043, d=0.54$. In this latter $t$-test, degrees of freedom were adjusted, because Levene's test indicated unequal variances, $F=5.02, p=.026$. These differences were small to moderate and were not expected to distort the results.

Across all waves, $11.9 \%$ of the data was missing. Although Little's (1988) Missing Completely at Random (MCAR) test was significant, $\chi^{2}(3424)=3663.29, p=$ .002 , the normed $\chi^{2}\left(\chi^{2} / d f\right)$ was only 1.07 , indicating a random pattern of missingness (Bollen, 1989). Therefore, cases with missing data were included in Mplus 7.11, using Full Information Maximum Likelihood (FIML; Muthén \& Muthén, 1998-2012).

\section{Procedure}

Participants were recruited from various Dutch elementary schools. Families received information about the RADAR project. Adolescents were asked to invite their best friend to the study. All participating target adolescents, best friends, and parents of these adolescents provided written informed consent. During annual home visits, target adolescents and best friends filled out various questionnaires under supervision of a trained research assistant. Every wave, adolescents and their friends received $€ 15$ as a reward for their participation. The ethical-medical committee of University Medical Centre Utrecht has approved the RADAR study.

\section{Measures}

Identity. Educational identity dimensions were assessed with the UtrechtManagement of Identity Commitments Scale (U-MICS; Crocetti, Rubini, \& Meeus, 2008). This self-report questionnaire contains five items measuring Commitment (e.g., "My education gives me certainty in life"), five items measuring In-depth Exploration 
(e.g., "I think a lot about my education"), and three items measuring Reconsideration (e.g., "I often think it would be better to try to find a different education"). Adolescents answered on a 5-point scale from 1 (completely true) to 5 (completely untrue). Items were recoded so that higher values reflect a higher level of commitment, in-depth exploration, and reconsideration. The U-MICS was shown to be a valid measure of adolescents' identity (Crocetti, Rubini, \& Meeus, 2008; Crocetti, Rubini, Luyckx, \& Meeus, 2008). In the present study, Cronbach's alphas among target adolescents and best friends ranged across waves from .91 to .96 for commitment, from .80 to .87 for indepth exploration, and from .88 to .92 for reconsideration.

Perceived balanced relatedness. The balanced relatedness scale (Shulman, Laursen, Kalman, \& Karpovsky, 1997) was used to measure target adolescents’ perceptions of the balanced relatedness provided by their best friend. Target adolescents rated to what extent the seven items characterized their friend (e.g., "My best friend respects my decisions") on a 4-point scale from 1 (absolutely disagree) to 4 (absolutely agree). Previous research supported the validity of this scale in adolescent friendships (Selfhout et al., 2009; Shulman, Laursen et al., 1997). In the present study, Cronbach's alphas ranged from .87 to .92 across waves.

\section{Strategy of Analysis}

To investigate the over-time associations between adolescents' and best friends' educational identities and perceived best friends' balanced relatedness, we analyzed three cross-lagged panel models in Mplus 7.11 (Muthén \& Muthén, 1998-2012; see Figure 1). Each model focused on one of the three educational identity dimensions among adolescents and their best friends (i.e., commitment, in-depth exploration, and reconsideration). Each model contained the following parameters: (a) 1- and 2-year 
stability paths of adolescents' educational identity, best friends' educational identity, and balanced relatedness, (b) concurrent correlations between these three variables at $\mathrm{T} 1$, (c) concurrent correlations between the residuals of these three variables at $\mathrm{T} 2$ to T5, reflecting correlated change as well as correlated measurement error, (d) crosslagged effects between balanced relatedness and adolescents' educational identity, and (e) cross-lagged effects between adolescents' and best friends' educational identity.

A Full Information Robust Maximum Likelihood estimator was used to estimate all models (Satorra \& Bentler, 2001), for reasons of non-normally distributed variables. The fit of the models was considered to be acceptable by a comparative fit index (CFI) above .90 , and a root mean square error of approximation (RMSEA) below .08 (Byrne, 2012).

For each model we tested whether the model was time invariant, meaning that cross-lagged effects and correlated residuals could be constrained to be equal over time without worsening the model fit. In multi-group analyses we tested whether T1 associations, cross-lagged effects or correlated residuals could be constrained between stable $(n=162)$ and unstable friendships $(n=302)$ without worsening the model fit. In the group of stable friendships, adolescents had the same best friend participating at every wave. In the group of unstable friendships, different best friends participated across waves or at some waves no best friend participated. We compared the fit of different models by using chi-square difference tests, after correcting chi-squares with the scaling correction factor because MLR was used.

\section{Results}

Descriptive statistics and relative stability of the three educational identity dimensions and balanced relatedness are shown in Table 1. Correlations between 
adolescents' identity dimensions and balanced relatedness and between adolescents' and best friends' identity dimensions are shown in Table 2.

\section{Cross-Lagged Panel Models per Identity Dimension}

We analyzed three cross-lagged panel models, with each model focusing on one of the educational identity dimensions: educational commitment, in-depth exploration, and reconsideration.

Commitment. In the model for educational commitment, the model fit decreased significantly when all cross-lagged effects were constrained to be equal over time, compared to a model without time invariant constraints, $\Delta \chi^{2} \operatorname{SB}(12)=21.17, p=$ .048. Follow-up analyses on each cross-lagged effect showed that only the cross-lagged effect from adolescents' commitment on balanced relatedness varied significantly over time, $\Delta \chi^{2}{ }_{\mathrm{SB}}(3)=8.67, p=.034$. The other cross-lagged effects were time invariant ( $p \mathrm{~s} \geq$ $.243)$, as well as the correlated residuals, $\Delta \chi^{2} \mathrm{SB}(9)=10.69, p=.298$. Consequently, all cross-lagged effects and correlated residuals were constrained to be equal over time, except for the cross-lagged effect of adolescents' commitment on balanced relatedness. This resulted in a model with an acceptable model fit: $\chi^{2} \mathrm{sB}(71)=113.17, p=.001$, CFI $=.95, \mathrm{RMSEA}=.04,90 \% \mathrm{CI}$ of RMSEA $[.023, .048]$. Parameters of this model are provided in Table 3.

When comparing the associations and cross-lagged effects in the model between the groups of adolescents with stable and unstable friendships, we found the T1 association between adolescents' educational commitment and perceived balanced relatedness to differ, $\Delta \chi^{2} \mathrm{SB}(1)=4.05, p=.044$. At baseline, adolescents' commitment was related more strongly to their perception of their best friends' balanced relatedness in stable friendships compared to unstable friendships. The other T1 associations did not 
differ between stable and unstable friendships $(p \geq .704)$. Moreover, we found the time variant cross-lagged effect of adolescents' commitment on balanced relatedness to differ, $\Delta \chi^{2} \mathrm{SB}(4)=10.64, p=.031$. Within unstable friendships, adolescents' commitment only significantly predicted balanced relatedness from $\mathrm{T} 3$ to $\mathrm{T} 4$, and from T4 to T5. Within stable friendships, adolescents' commitment only significantly predicted balanced relatedness from T3 to T4. These effects showed that a higher level of adolescents' commitment predicted a small relative increase in balanced relatedness, as perceived by the adolescent. Within unstable friendships, this effect might consist of an influence as well as a selection effect, as some adolescents nominated different best friends and some nominated the same best friend across T3 to T4 and T4 to T5. Within stable friendships, this effect indicates an influence effect. The cross-lagged effect of adolescents' commitment on best friends' commitment also differed between stable and unstable friendships, $\Delta \chi_{\mathrm{SB}}^{2}(1)=7.52, p=.006$. Only within stable friendships, a higher level of adolescents' commitment unexpectedly predicted a small relative decrease in best friends' commitment.

The reversed cross-lagged effects from best friends' balanced relatedness and commitment on adolescents' commitment were not significant. Moreover, the residuals of balanced relatedness and adolescents' and their best friends' commitment were not significantly correlated. None of these non-significant cross-lagged effects or correlated residuals differed significantly between stable and unstable friendships ( $p$ s $\leq .242$ ).

In-depth exploration. In the model for educational in-depth exploration, all cross-lagged effects and correlated residuals could be constrained to be equal over time without worsening the model fit, $\Delta \chi^{2} \mathrm{SB}(12)=13.96, p=.303$ and $\Delta \chi^{2}{ }_{\mathrm{SB}}(9)=11.54, p=$ .241 , respectively. This resulted in a time invariant model with an acceptable model fit, 
$\chi_{\mathrm{SB}}^{2}(74)=110.16, p=.004, \mathrm{CFI}=.95, \operatorname{RMSEA}=.03,90 \% \mathrm{CI}$ of RMSEA $[.019, .045]$ Parameters of this model are provided in Table 4.

The cross-lagged effect of adolescents' in-depth exploration on balanced relatedness differed between stable and unstable friendships, $\Delta \chi^{2} \operatorname{sB}(1)=4.19, p=.041$. Only within stable friendships, a higher level of adolescents' in-depth exploration significantly predicted a slight relative increase in perceived balanced relatedness.

In this model, the reversed cross-lagged effect of balanced relatedness on indepth exploration and the cross-lagged effects between adolescents' and best friends' in-depth exploration were not significant. In addition, the residuals of adolescents' and best friends' in-depth exploration and balanced relatedness were not significantly associated. These cross-lagged effects and correlated residuals, as well as the T1 associations, did not differ significantly between stable and unstable friendships ( $p \mathrm{~s} \leq$ $.131)$.

Reconsideration. In the model for educational reconsideration all cross-lagged effects and correlated residuals could be constrained to be equal over time without worsening the model fit, $\Delta \chi^{2} \mathrm{SB}(12)=17.73, p=.124$ and $\Delta \chi^{2}{ }_{\mathrm{SB}}(9)=6.92, p=.645$, respectively. This resulted in a time invariant model with an acceptable model fit: $\chi_{\mathrm{SB}}^{2}(74)=108.52, p=.006, \mathrm{CFI}=.94, \mathrm{RMSEA}=.03,90 \% \mathrm{CI}$ of RMSEA $[.018, .044]$. Parameters of this model are provided in Table 5.

In this model, balanced relatedness modestly and negatively predicted adolescents' reconsideration across waves, indicating that a higher level of perceived balanced relatedness predicted a small relative decrease in adolescents' reconsideration over time. Furthermore, the residuals of balanced relatedness and adolescents' reconsideration were significantly associated across all waves. A relative increase in 
perceived balanced relatedness was slightly associated with a relative decrease in adolescents' reconsideration.

The reversed cross-lagged effect of adolescents' reconsideration on balanced relatedness and the cross-lagged effects between adolescents' and best friends' reconsideration were not significant. Furthermore, the residuals of best friends' reconsideration did not correlate significantly with adolescents' reconsideration or with perceived balanced relatedness. These cross-lagged effects and correlated residuals, as well as the T1 associations, did not differ between stable and unstable friendships ( $p \leq$ $.099)$.

\section{Discussion}

The aim of this 4-year longitudinal study was to examine whether adolescents' educational identity is associated over time with adolescents' perceived balanced relatedness provided by their best friend and their best friend's educational identity. Our findings provide support for over-time associations between adolescents' educational identity and perceived balanced relatedness, but these associations took on a different form for each of the three identity dimensions. That is, the perception of best friends' balanced relatedness was negatively related to adolescents' educational reconsideration one year later. In turn, adolescents' educational in-depth exploration and, in an inconsistent pattern, educational commitment were positively associated with perceived balanced relatedness of friends one year later. Our findings provide no support for positive over-time associations between adolescents' and best friends' educational identity.

\section{Friends' Balanced Relatedness}


The most consistent finding of this study was that a higher level of perceived balanced relatedness provided by best friends was related to lower educational reconsideration. These associations were small, but consistent over time, as evident in the T1 correlation, correlated changes, and relations over time of higher balanced relatedness with a relative decrease in adolescents' educational reconsideration one year later. This finding is in line with the idea that friendships form a fruitful ground for identity formation (Erikson, 1968), especially when they are intimate (McLean \& Jennings, 2012). Adolescents might feel supported in their educational choices by a best friend they perceive to be high on balanced relatedness. As a result, they might search less for alternatives. Reconsideration of commitment is thought to reflect the troublesome and crisis-like aspect of identity formation, and is positively associated with depression and anxiety (Crocetti, Klimstra, Keijsers, Hale, \& Meeus, 2009; Crocetti, Rubini, \& Meeus, 2008). Our findings did not show associations of perceived balanced relatedness with adolescents' educational commitment and in-depth exploration one year later. Thus, adolescents' perception of their best friends' balanced relatedness does not relate to the adaptive processes of educational identity formation over time, but might play a role in decreasing adolescents' problematic educational reconsideration.

The adaptive processes of educational identity formation were also associated with adolescents' perceptions of their best friends' balanced relatedness over time. Specifically, a higher level of educational in-depth exploration was related to a relative increase in adolescents' perceived balanced relatedness one year later. In addition, at several time points, a stronger educational commitment was associated with a relative increase in perceived balanced relatedness. No associations of reconsideration with 
perceived balanced relatedness one year later were found. These findings are in line with theory suggesting that the formation of a coherent identity stimulates the development of intimate friendships, characterized by a high level of balanced relatedness (Erikson, 1963; Bauminger et al., 2008). Adolescents who have a stronger educational commitment and have explored this commitment in-depth might be less sensitive to confronting ideas of their friend, and therefore perceive a higher level of balanced relatedness.

Although we found significant associations of educational commitment and indepth exploration with perceived balanced relatedness one year later, these associations varied with the age of adolescents and the stability of adolescent friendships. The overtime association of adolescents' educational commitment with perceived balanced relatedness was significant only when adolescents were somewhat older, that is, about 16 to 18 years old. This finding might indicate the increasing saliency of educational identity with increasing age (Arnett, 2000), possibly triggered by the transition to tertiary education (Kalakoski \& Nurmi, 1998). When identity becomes more salient, it might be related more strongly to psychosocial functioning and relationships. Moreover, adolescents' educational commitment and in-depth exploration were associated over time with perceived balanced relatedness within stable friendships, but the association of educational commitment was found across even more time points within unstable friendships. As adolescents within the group of unstable friendships sometimes brought the same and sometimes a different best friend, these over-time associations might indicate both influence and selection effects. Therefore, it is possible that adolescents with a stronger educational commitment deselect a best friend who they perceive as low 
on balanced relatedness and select a best friend who they perceive as higher on balanced relatedness.

\section{Friends' Identity}

Unexpectedly, adolescents' educational in-depth exploration and reconsideration were not related over time to their best friends' level on these respective dimensions. However, adolescents' stronger educational commitment was associated with a small relative decrease in their best friends' educational commitment one year later within stable friendships. This finding contradicts our hypothesis and previous studies (Akers et al., 1998; Dumas, 2011). Moreover, this finding was in contrast with the correlations between these variables, which were non-significant or significant and positive, and might therefore reflect a suppressor effect.

An explanation for the overall absence of over-time associations between adolescents' and best friends' educational identities might be that the educational identity dimensions are not very explicit within adolescent friendships. Adolescents might not perceive their best friends' actual educational identity dimensions and will not be influenced by them, as perception is vital for influence (Ryan, 2010). Possibly adolescents might talk more about their educational identity with their best friend when confronted with salient institutionalized moments of choice, such as the transition to tertiary education. As the adolescents in the current study did not experience these moments of choice at the same time, it might be difficult to find cross-lagged effects between best friends' educational identities.

\section{Limitations}

Despite the multi-informant longitudinal design of our study, several limitations should be noted. First, our findings do not provide support for the mechanisms by which 
adolescents' educational identity and perceived best friends' balanced relatedness predict each other over time. Future qualitative or experimental research might examine whether adolescents feel supported in their identity development by a friend with a high level of balanced relatedness. In addition, it might be examined whether adolescents high on commitment and in-depth exploration are less sensitive to confronting ideas of their friend. Second, although our study did not show the hypothesized positive associations between best friends' educational identities, future research should assess friends' feedback on the target's identity more directly to examine the assumption of identity control theory that adolescents' identity will be affected by self-relevant information (Kerpelman et al., 1997). Third, from our findings we cannot conclude whether adolescents' perception or the actual degree of best friends' balanced relatedness is associated more strongly with adolescents' educational identity. Future studies with different balanced relatedness measures, such as reports by friends themselves or observations (e.g., Dumas, 2011), might examine this. However, it is likely that adolescents' educational identity is more influenced by and has more influence on adolescents' perception of balanced relatedness than the actual degree of balanced relatedness (Ryan, 2010). Fourth, the present study did not focus on specific moments at which adolescents have to make educational choices, which might trigger the saliency of adolescents' educational identities. This might have led to weaker findings and could be an explanation for the inconsistent findings regarding the associations between adolescents' educational commitment and balanced relatedness one year later. Future longitudinal research across educational transitions is needed, both to replicate the current findings and to examine when and how adolescents' educational identity influences friendships. 


\section{Conclusion}

The findings of this study did not support the hypothesis that adolescent best friends' educational identity dimensions are positively associated and become more similar over time. However, this study shows that adolescents' educational identity dimensions are associated over time with adolescents' perceptions of their best friends' balanced relatedness. These over-time associations might be caused by influence effects, but the cross-lagged effect of commitment on balanced relatedness might also reflect selection effects. The findings indicate a possible increasing saliency of adolescents' educational identity over time, as adolescents with a strong educational commitment experienced an increasing level of balanced relatedness only in late adolescence. Most of the over-time associations were small. However, the associations from in-depth exploration to balanced relatedness, and from balanced relatedness to reconsideration were consistent over time. As these effects accumulate over time they might eventually play an important role in adolescents' educational identity development and the development of balanced relatedness in friendships. 


\section{References}

Akers, J. F., Jones, R. M., \& Coyl, D. D. (1998). Adolescent friendship pairs: Similarities in identity status development, behaviors, attitudes, and intentions. Journal of Adolescent Research, 13, 178-201. doi:10.1177/0743554898132005

Arnett, J. J. (2000). Emerging adulthood: A theory of development from the late teens through the twenties. American Psychologist, 55, 469-480. doi:10.1037//0003066X.55.5.469

Baumeister, R. F., \& Muraven, M. (1996). Identity as adaptation to social, cultural, and historical context. Journal of Adolescence, 19, 405-416. doi:10.1006/jado.1996.0039

Bauminger, N., Finzi-Dottan, R., Chason, S., \& Har-Even, D. (2008). Intimacy in adolescent friendships: The roles of attachment, coherence, and self-discloure. Journal of Social and Personal Relationships, 25, 409-428. doi:10.1177/0265407508090866

Bollen, K. (1989). Structural equations with latent variables. New York, NY: Wiley.

Bosma, H. A., \& Kunnen, E. S. (2001). Determinants and mechanisms in ego identity development: A review and synthesis. Developmental Review, 21, 39-66. doi:10.1006/drev.2000.0514

Branje, S., Frijns, T., Finkenauer, C., Engels, R., \& Meeus, W. (2007). You are my best friend: Commitment and stability in adolescents' same-sex friendships. Personal Relationships, 14, 587-603. doi:10.1111/j.1475-6811.2007.00173.x

Branje, S., Laninga-Wijnen, L., Yu, R., \& Meeus, W. (2014). Associations among school and friendship identity in adolescence and romantic relationships and 
work in emerging adulthood. Emerging Adulthood, 2, 6-16. doi:10.1177/2167696813515851

Brechwald, W. A., \& Prinstein, M. J. (2011). Beyond homophily: A decade of advances in understanding peer influence processes. Journal of Research on Adolescence, 21, 166-179. doi:10.1111/j.1532-7795.2010.00721.x

Byrne, B. M. (2012). Structural equation modeling with Mplus: Basic concepts, applications, and programming. New York, NY: Taylor \& Francis.

Crocetti, E., Klimstra, T., Keijsers, L., Hale, W. W., \& Meeus, W. (2009). Anxiety trajectories and identity development in adolescence: A five-wave longitudinal study. Journal of Youth and Adolescence, 38, 839-849. doi:10.1007/s10964-008$9302-y$

Crocetti, E., Rubini, M., Luyckx, K., \& Meeus, W. (2008). Identity formation in early and middle adolescents from various ethnic groups: From three dimensions to five statuses. Journal of Youth and Adolescence, 37, 983-996. doi:10.1007/s10964-007-9222-2

Crocetti, E., Rubini, M., \& Meeus, W. (2008). Capturing the dynamics of identity formation in various ethnic groups: Development and validation of a threedimensional model. Journal of Adolescence, 31, 207-222. doi:10.1016/j.adolescence.2007.09.002

Doumen, S., Smits, I., Luyckx, K., Duriez, B., Vanhalst, J., Verschueren, K., \& Goossens, L. (2012). Identity and perceived peer relationship quality in emerging adulthood: The mediating role of attachment-related emotions. Journal of Adolescence, 35, 1417-1425. doi:10.1016/j.adolescence.2012.01.003 
Dumas, T. M. (2011). An observational assessment of peer group contributions to adolescent identity development (Doctoral dissertation). Retrieved from University of Western Ontario - Electronic Thesis and Dissertation Repository. (Paper 168)

Erikson, E. H. (1963). Childhood and society (2nd ed.). New York, NY: Norton.

Erikson, E. H. (1968). Identity: Youth and crisis. New York, NY: Norton.

Johnson, H. D. (2012). Relationship duration moderation of identity status differences in emerging adults' same-sex friendship intimacy. Journal of Adolescence, 35, 1515-1525. doi:10.1016/j.adolescence.2012.07.001

Kalakoski, V., \& Nurmi, J. (1998). Identity and educational transitions: Age differences in adolescent exploration and commitment related to education, occupation, and family. Journal of Research on Adolescence, 8, 29-47. doi:10.1207/s15327795jra0801_2

Kerpelman, J. L., Pittman, J. F., \& Lamke, L. K. (1997). Toward a microprocess perspective on adolescent identity development: An identity control theory approach. Journal of Adolescent Research, 12, 325-346.

doi:10.1177/0743554897123002

Little, R. J. A. (1988). A test of missing completely at random for multivariate data with missing values. Journal of the American Statistical Association, 83, 1198-1202. doi:10.1080/01621459.1988.10478722

Luyckx, K., Soenens, B., Goossens, L., \& Vansteenkiste, M. (2007). Parenting, identity formation, and college adjustment: A mediation model with longitudinal data. Identity: An International Journal of Theory and Research, 7, 309-330. doi:10.1080/15283480701600785 
Marcia, J. E. (1966). Development and validation of ego-identity status. Journal of Personality and Social Psychology, 3, 551-558. doi:10.1037/h0023281

McLean, K. C., \& Jennings, L. E. (2012). Teens telling tales: How maternal and peer audiences support narrative identity development. Journal of Adolescence, 35, 1455-1469. doi:10.1016/j.adolescence.2011.12.005

Mclean, K. C., \& Pasupathi, M. (2010). Narrative development in adolescence: Creating the storied self. New York, NY: Springer.

Meeus, W., Iedema, J., Helsen, M., \& Vollebergh, W. (1999). Patterns of adolescent identity development: Review of literature and longitudinal analysis. Developmental Review, 19, 419-461. doi:10.1006/drev.1999.0483

Meeus, W., Van de Schoot, R., Keijsers, L., Schwartz, S. J., \& Branje, S. (2010). On the progression and stability of adolescent identity formation. A five-wave longitudinal study in early-to-middle and middle-to-late adolescence. Child Development, 81, 1565-1581. doi:10.1111/j.1467-8624.2010.01492.x

Muthén, L. K., \& Muthén, B. O. (1998-2012). Mplus user's guide (7th ed.). Los Angeles, CA: Muthén \& Muthén.

Reis, O., \& Youniss, J. (2004). Patterns in identity change and development in relationships with mothers and friends. Journal of Adolescent Research, 19, 3144. doi:10.1177/0743558403258115

Ryan, A. M. (2010). Peer groups as a context for the socialization of adolescents' motivation, engagement, and achievement in school. Educational Psychologist, 35, 101-111. doi:10.1207/S15326985EP3502_4 
Satorra, A., \& Bentler, P. M. (2001). A scaled difference chi-square test statistic for moment structure analysis. Psychometrika, 66, 507-514. doi:10.1007/BF02296192

Selfhout, M. H. W., Branje, S. J. T., \& Meeus, W. H. J. (2009). Developmental trajectories of perceived friendship intimacy, constructive problem solving, and depression from early to late adolescence. Journal of Abnormal Child Psychology, 37, 251-264. doi:10.1007/s10802-008-9273-1

Shulman, S., \& Knafo, D. (1997). Balancing closeness and individuality in adolescent close relationships. International Journal of Behavioral Development, 21, 687702. doi:10.1080/016502597384622

Shulman, S., Laursen, B., Kalman, Z., \& Karpovsky, S. (1997). Adolescent intimacy revisited. Journal of Youth and Adolescence, 26, 597-617. doi:10.1023/A:1024586006966

Thorne, A., \& Shapiro, L. A. (2011). Testing, testing: Everyday storytelling and the construction of adolescent identity. In E. Amsel \& J. Smetana (Eds.), Adolescent vulnerabilities and opportunities (pp. 117-138). Cambridge, England: Cambridge University Press.

van Lier, P. A. C., Frijns, T., den Exter Blokland, E., Neumann, A., Koot, H. M., \& Meeus, W. (2008). The RADAR study: Design, description of sample and validation of cohort assignment. Unpublished manuscript.

Weeks, T. L., \& Pasupathi, M. (2010). Autonomy, identity, and narrative construction with parents and friends. In K. C. Mclean \& M. Pasupathi (Eds.), Narrative development in adolescence: Creating the storied self (pp. 65-91). New York, NY: Springer. 
$\underline{\mathrm{T} 1}$

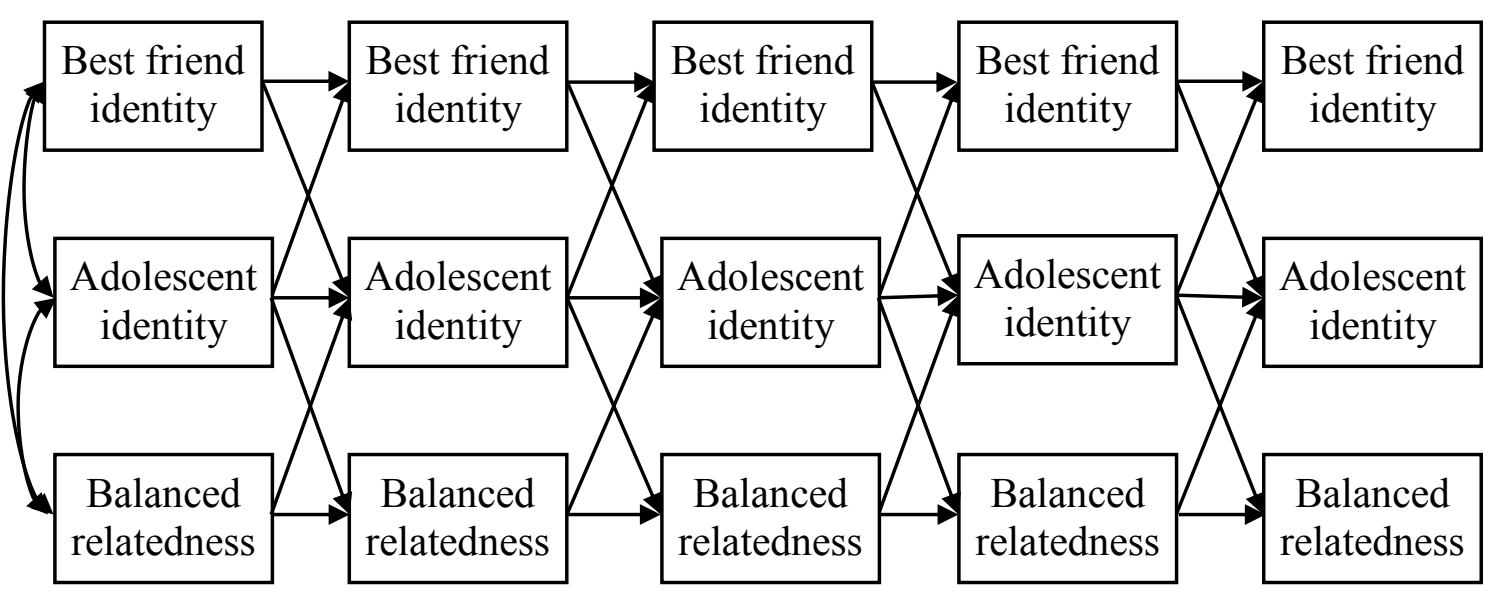

Figure 1. Cross-lagged panel model. Although not displayed for reasons of clarity, this model includes associations between all variables within every wave and 2 year stability paths for adolescent and best friend identity and balanced relatedness. 


\section{FRIENDS' ROLE IN EDUCATIONAL IDENTITY FORMATION}

Table 1

Descriptives and Relative Stability of Adolescents' and Best Friends' Educational Identity, and Balanced Relatedness

\begin{tabular}{|c|c|c|c|c|c|c|c|c|c|c|c|c|c|c|}
\hline \multirow[b]{2}{*}{ Variable } & \multicolumn{2}{|l|}{ T1 } & \multicolumn{2}{|l|}{$\mathrm{T} 2$} & \multicolumn{2}{|c|}{ T3 } & \multicolumn{2}{|l|}{$\mathrm{T} 4$} & \multicolumn{2}{|l|}{ T5 } & \multicolumn{4}{|c|}{ Relative stability } \\
\hline & $M$ & $S D$ & $M$ & $S D$ & $M$ & $S D$ & $M$ & $S D$ & $M$ & $S D$ & $\mathrm{~T} 1-\mathrm{T} 2$ & $\mathrm{~T} 2-\mathrm{T} 3$ & T3-T4 & T4-T5 \\
\hline \multicolumn{15}{|l|}{ Commitment } \\
\hline Adolescent & 18.11 & 4.13 & 17.83 & 4.38 & 18.00 & 4.41 & 18.41 & 4.51 & 18.34 & 4.41 & $.41 * * *$ & $.47 * * *$ & $.45^{* * *}$ & $.53 * * *$ \\
\hline Best friend & 17.74 & 3.95 & 18.09 & 3.98 & 18.03 & 3.78 & 18.37 & 4.18 & 18.20 & 4.09 & $.43 * * *$ & $.39 * * *$ & $.40 * * *$ & $.45^{* * *}$ \\
\hline \multicolumn{15}{|c|}{ In-depth exploration } \\
\hline Adolescent & 15.77 & 3.90 & 16.15 & 3.92 & 15.74 & 4.25 & 16.13 & 4.14 & 16.25 & 3.92 & $.37 * * *$ & $.37 * * *$ & $.41 * * *$ & $.52 * * *$ \\
\hline Best friend & 15.26 & 3.86 & 15.99 & 3.76 & 15.12 & 3.80 & 15.41 & 3.79 & 15.87 & 3.70 & $.33 * * *$ & $.36 * * *$ & $.42 * * *$ & $.32 * * *$ \\
\hline \multicolumn{15}{|c|}{ Reconsideration } \\
\hline Adolescent & 5.95 & 2.91 & 5.82 & 2.62 & 5.91 & 2.89 & 5.89 & 3.10 & 6.16 & 3.10 & $.34 * * *$ & $.43 * * *$ & $.27 * * *$ & $.38 * * *$ \\
\hline Best friend & 5.69 & 2.83 & 5.80 & 2.83 & 5.84 & 2.91 & 5.75 & 3.04 & 5.99 & 3.03 & $.33 * * *$ & $.28 * * *$ & $.34 * * *$ & $.33 * * *$ \\
\hline \multicolumn{15}{|c|}{ Balanced relatedness } \\
\hline Adolescent & 22.34 & 2.95 & 22.34 & 2.95 & 22.16 & 2.96 & 22.16 & 3.25 & 21.90 & 3.37 & $.37 * * *$ & $.46^{* * *}$ & $.32 * * *$ & $.36 * * *$ \\
\hline
\end{tabular}

$* * * p<.001$ 


\section{FRIENDS' ROLE IN EDUCATIONAL IDENTITY FORMATION}

Table 2

Correlations Between Adolescents' Educational Identity and Balanced Relatedness and Between Adolescents' and Best Friends' Educational Identities

\begin{tabular}{|c|c|c|c|c|c|c|c|c|c|c|c|c|c|c|c|}
\hline & \multicolumn{15}{|c|}{ Target adolescents' educational identity } \\
\hline & \multicolumn{5}{|c|}{ Commitment } & \multicolumn{5}{|c|}{ In-depth exploration } & \multicolumn{5}{|c|}{ Reconsideration } \\
\hline & $\mathrm{T} 1$ & $\mathrm{~T} 2$ & T3 & $\mathrm{T} 4$ & T5 & T1 & $\mathrm{T} 2$ & T3 & $\mathrm{T} 4$ & T5 & T1 & $\mathrm{T} 2$ & T3 & $\mathrm{T} 4$ & $\mathrm{~T} 5$ \\
\hline \multicolumn{16}{|c|}{ Balanced relatedness } \\
\hline $\mathrm{T} 1$ & $.16^{* * *}$ & .06 & $.15^{* *}$ & .09 & .07 & .09 & .00 & .03 & .02 & .00 & $-.22 * * *$ & $-.15 * *$ & -.09 & -.07 & $-.17 * *$ \\
\hline $\mathrm{T} 2$ & .07 & .06 & $.14 * *$ & -.01 & .05 & .00 & .06 & .07 & .00 & .03 & -.09 & $-.12 * *$ & -.09 & .04 & -.05 \\
\hline $\mathrm{T} 3$ & .07 & .05 & .07 & .02 & $.14^{* *}$ & .01 & .05 & .02 & -.06 & .02 & $-.17 * * *$ & -.08 & $-.11 *$ & .02 & $-.13 *$ \\
\hline $\mathrm{T} 4$ & $.12 *$ & $.20 * * *$ & $.22 * * *$ & $.24 * * *$ & $.22 * * *$ & .03 & $.11^{*}$ & .07 & .05 & .04 & $-.16 * *$ & $-.10 *$ & -.09 & $-.14 * *$ & $-.24 * * *$ \\
\hline T5 & $.13^{*}$ & $.19 * * *$ & $.17 * *$ & $.24 * * *$ & $.19 * * *$ & $.15^{* *}$ & $.17 * *$ & .04 & .08 & $.14 * *$ & $-.13 *$ & $-.15 * *$ & $-.12 *$ & $-.17 * *$ & $-.13^{*}$ \\
\hline
\end{tabular}

Best friends' educational identity

\begin{tabular}{|c|c|c|c|c|c|c|c|c|c|c|c|c|c|c|c|}
\hline $\mathrm{T} 1$ & .09 & .07 & .06 & .02 & -.06 & $.11 *$ & .08 & .06 & .05 & .05 & $.13 * *$ & .03 & .10 & $.10 *$ & .10 \\
\hline $\mathrm{T} 2$ & .01 & .04 & $.11 *$ & $.12 *$ & .04 & -.03 & .02 & .03 & .03 & .00 & .08 & .05 & .09 & $.11 *$ & $.17 * *$ \\
\hline T3 & .03 & .03 & $.14^{* *} *$ & .09 & .02 & .07 & .08 & $.11^{*}$ & $.12 *$ & .04 & .03 & .06 & .09 & .04 & .01 \\
\hline $\mathrm{T} 4$ & -.01 & -.05 & -.03 & .05 & -.02 & .04 & .02 & -.06 & -.01 & -.01 & .05 & $.12 *$ & -.04 & $.11 *$ & .09 \\
\hline T5 & .00 & .00 & $.11 *$ & .04 & .00 & .05 & $.11^{*}$ & .01 & -.02 & $.11^{*}$ & .01 & .07 & .06 & .03 & .09 \\
\hline
\end{tabular}

Note. Best friends' educational identity = Educational identity dimensions among best friends, corresponding to the educational identity dimension of target adolescents.

$* p<.05 . * * p<.01 . * * * p<.001$. 


\section{FRIENDS’ ROLE IN EDUCATIONAL IDENTITY FORMATION}

Table 3

Parameter Estimates of the Cross-lagged Panel Model for Adolescents' and Best Friends' Educational Commitment

\begin{tabular}{|c|c|c|c|c|c|c|c|c|c|c|c|c|}
\hline \multirow[b]{2}{*}{ Parameter } & \multicolumn{3}{|c|}{ T1-T2 } & \multicolumn{3}{|c|}{ T2-T3 } & \multicolumn{3}{|c|}{ T3-T4 } & \multicolumn{3}{|c|}{ T4-T5 } \\
\hline & $B$ & $S E$ & $\beta$ & $B$ & $S E$ & $\beta$ & $B$ & $S E$ & $\beta$ & $B$ & $S E$ & $\beta$ \\
\hline \multicolumn{13}{|l|}{1 Year stability paths } \\
\hline Balanced relatedness & 0.38 & .06 & $.37 * * *$ & 0.38 & .05 & $.37 * * *$ & 0.29 & .07 & $.27 * * *$ & 0.27 & .09 & $.26^{* *}$ \\
\hline Commitment (A) & 0.42 & .06 & $.40 * * *$ & 0.39 & .06 & $.39 * * *$ & 0.30 & .07 & $.29 * * *$ & 0.45 & .07 & $.45 * * *$ \\
\hline Commitment (F) & 0.44 & .05 & $.43 * * *$ & 0.29 & .06 & $.31 * * *$ & 0.38 & .07 & $.35 * * *$ & 0.38 & .06 & $.39 * * *$ \\
\hline \multicolumn{13}{|l|}{ T1 Associations } \\
\hline Commitment (A) - Balanced relatedness & 1.95 & .62 & $.16^{* *}$ & & & & & & & & & \\
\hline Stable friendships & 3.48 & .96 & $.28 * * *$ & & & & & & & & & \\
\hline Unstable friendships & 1.05 & .80 & .09 & & & & & & & & & \\
\hline Commitment (A) - Commitment (F) & 1.61 & .78 & $.10 *$ & & & & & & & & & \\
\hline Balanced relatedness - Commitment $(\mathrm{F})$ & 0.88 & .51 & .08 & & & & & & & & & \\
\hline \multicolumn{13}{|l|}{ Cross-lagged effects } \\
\hline Balanced relatedness $\rightarrow$ Commitment $(\mathrm{A})$ & 0.06 & .04 & .04 & 0.06 & .04 & .04 & 0.06 & .04 & .04 & 0.06 & .04 & .05 \\
\hline \multicolumn{13}{|l|}{ Commitment $(\mathrm{A}) \rightarrow$ Balanced relatedness } \\
\hline Stable friendships & 0.05 & .07 & .08 & 0.09 & .05 & .13 & 0.22 & .11 & $.28 *$ & -0.02 & .06 & -.03 \\
\hline Unstable friendships & -0.02 & .04 & -.02 & -0.03 & .04 & -.05 & 0.11 & .05 & $.15^{*}$ & 0.19 & .07 & $.24 * *$ \\
\hline Commitment $(\mathrm{F}) \rightarrow$ Commitment $(\mathrm{A})$ & 0.03 & .03 & .02 & 0.03 & .03 & .03 & 0.03 & .03 & .02 & 0.03 & .03 & .03 \\
\hline \multicolumn{13}{|l|}{ Commitment $(\mathrm{A}) \rightarrow$ Commitment $(\mathrm{F})$} \\
\hline Stable friendships & -0.09 & .04 & $-.08 *$ & -0.09 & .04 & $-.10 *$ & -0.09 & .04 & $-.08 *$ & -0.09 & .04 & $-.09 *$ \\
\hline \multirow[t]{3}{*}{ Unstable friendships } & 0.02 & .03 & .02 & 0.02 & .03 & .02 & 0.02 & .03 & .02 & 0.02 & .03 & .02 \\
\hline & \multicolumn{3}{|c|}{$\mathrm{T} 2$} & \multicolumn{3}{|c|}{$\mathrm{T} 3$} & \multicolumn{3}{|c|}{$\mathrm{T} 4$} & \multicolumn{3}{|c|}{ T5 } \\
\hline & $B$ & $S E$ & $\beta$ & $B$ & $S E$ & $\beta$ & $B$ & $S E$ & $\beta$ & $B$ & $S E$ & $\beta$ \\
\hline \multicolumn{13}{|l|}{ Correlated residuals } \\
\hline Commitment (A) - Balanced relatedness & 0.46 & .32 & .04 & 0.46 & .32 & .05 & 0.46 & .32 & .04 & 0.46 & .32 & .04 \\
\hline Commitment $(\mathrm{A})-$ Commitment $(\mathrm{F})$ & 0.68 & .38 & .05 & 0.68 & .38 & .05 & 0.68 & .38 & .05 & 0.68 & .38 & .05 \\
\hline Balanced relatedness - Commitment $(\mathrm{F})$ & -0.04 & .28 & -.01 & -0.04 & .28 & -.01 & -0.04 & .28 & .00 & -0.04 & .28 & .00 \\
\hline
\end{tabular}

Note. $(\mathrm{A})=$ of the target adolescents; $(\mathrm{F})=$ of the best friends. 2-year stability paths were estimated but were omitted from this table.

$* p<.05$. ** $p<.01 . * * * p<.001$. 


\section{FRIENDS’ ROLE IN EDUCATIONAL IDENTITY FORMATION}

Table 4

Parameter Estimates of the Cross-lagged Panel Model for Adolescents' and Best Friends' Educational In-depth Exploration

\begin{tabular}{|c|c|c|c|c|c|c|c|c|c|c|c|c|}
\hline \multirow[b]{2}{*}{ Parameter } & \multicolumn{3}{|c|}{ T1-T2 } & \multicolumn{3}{|c|}{ T2-T3 } & \multicolumn{3}{|c|}{ T3-T4 } & \multicolumn{3}{|c|}{ T4-T5 } \\
\hline & $B$ & $S E$ & $\beta$ & $B$ & $S E$ & $\beta$ & $B$ & $S E$ & $\beta$ & $B$ & $S E$ & $\beta$ \\
\hline \multicolumn{13}{|l|}{1 Year stability paths } \\
\hline Balanced relatedness & 0.37 & .06 & $.37 * * *$ & 0.37 & .05 & $.37 * * *$ & 0.29 & .07 & $.27 * * *$ & 0.31 & .09 & $.30 * * *$ \\
\hline In-depth exploration (A) & 0.37 & .05 & $.37 * * *$ & 0.33 & .07 & $.30 * * *$ & 0.34 & .06 & $.35 * * *$ & 0.43 & .06 & $.46 * * *$ \\
\hline In-depth exploration $(F)$ & 0.33 & .05 & $.33 * * *$ & 0.31 & .06 & $.30 * * *$ & 0.36 & .06 & $.36 * * *$ & 0.25 & .07 & $.26 * * *$ \\
\hline \multicolumn{13}{|l|}{ T1 Associations } \\
\hline In-depth exploration $(\mathrm{A})$ - Balanced relatedness & 1.02 & .66 & .09 & & & & & & & & & \\
\hline In-depth exploration $(\mathrm{A})$ - In-depth exploration $(\mathrm{F})$ & 1.59 & .73 & $.11 *$ & & & & & & & & & \\
\hline Balanced relatedness - In-depth exploration $(\mathrm{F})$ & 0.81 & .52 & .07 & & & & & & & & & \\
\hline \multicolumn{13}{|l|}{ Cross-lagged effects } \\
\hline Balanced relatedness $\rightarrow$ In-depth exploration (A) & -0.01 & .03 & -.01 & -0.01 & .03 & -.01 & -0.01 & .03 & -.01 & -0.01 & .03 & -.01 \\
\hline \multicolumn{13}{|l|}{ In-depth exploration $(\mathrm{A}) \rightarrow$ Balanced relatedness } \\
\hline Stable friendships & 0.06 & .03 & $.09 *$ & 0.06 & .03 & $.09 *$ & 0.06 & .03 & $.08 *$ & 0.06 & .03 & $.09 *$ \\
\hline Unstable friendships & 0.00 & .03 & .00 & 0.00 & .03 & .00 & 0.00 & .03 & .00 & 0.00 & .03 & .00 \\
\hline In-depth exploration $(\mathrm{F}) \rightarrow$ In-depth exploration $(\mathrm{A})$ & 0.04 & .03 & .04 & 0.04 & .03 & .04 & 0.04 & .03 & .04 & 0.04 & .03 & .04 \\
\hline \multirow[t]{3}{*}{ In-depth exploration $(\mathrm{A}) \rightarrow$ In-depth exploration $(\mathrm{F})$} & -0.03 & .02 & -.03 & -0.03 & .02 & -.03 & -0.03 & .02 & -.03 & -0.03 & .02 & -.03 \\
\hline & \multicolumn{3}{|c|}{$\mathrm{T} 2$} & \multicolumn{3}{|c|}{ T3 } & \multicolumn{3}{|c|}{$\mathrm{T} 4$} & \multicolumn{3}{|c|}{ T5 } \\
\hline & $B$ & SE & $\beta$ & $B$ & $S E$ & $\beta$ & $B$ & $S E$ & $\beta$ & $B$ & $S E$ & $\beta$ \\
\hline \multicolumn{13}{|l|}{ Correlated residuals } \\
\hline In-depth exploration $(\mathrm{A})$ - Balanced relatedness & 0.41 & .30 & .04 & 0.41 & .30 & .04 & 0.41 & .30 & .04 & 0.41 & .30 & .04 \\
\hline In-depth exploration (A) - In-depth exploration (F) & 0.63 & .33 & .05 & 0.63 & .33 & .05 & 0.63 & .33 & .05 & 0.63 & .33 & .06 \\
\hline Balanced relatedness - In-depth exploration $(\mathrm{F})$ & -0.08 & .26 & -.01 & -0.08 & .26 & -.01 & -0.08 & .26 & -.01 & -0.08 & .26 & -.01 \\
\hline
\end{tabular}

Note. $(\mathrm{A})=$ of the target adolescents; $(\mathrm{F})=$ of the best friends. 2-year stability paths were estimated but were omitted from this table.

$* p<.05 . * * p<.01 . * * * p<.001$. 


\section{FRIENDS' ROLE IN EDUCATIONAL IDENTITY FORMATION}

Table 5

Parameter Estimates of the Cross-lagged Panel Model for Adolescents' and Best Friends' Educational Reconsideration

\begin{tabular}{|c|c|c|c|c|c|c|c|c|c|c|c|c|}
\hline \multirow[b]{2}{*}{ Parameter } & \multicolumn{3}{|c|}{ T1-T2 } & \multicolumn{3}{|c|}{ T2-T3 } & \multicolumn{3}{|c|}{ T3-T4 } & \multicolumn{3}{|c|}{ T4-T5 } \\
\hline & $B$ & $S E$ & $\beta$ & $B$ & $S E$ & $\beta$ & $B$ & $S E$ & $\beta$ & $B$ & $S E$ & $\beta$ \\
\hline \multicolumn{13}{|l|}{1 Year stability paths } \\
\hline Balanced relatedness & 0.36 & .06 & $.36 * * *$ & 0.38 & .05 & $.37 * * *$ & 0.29 & .07 & $.27 * * *$ & 0.31 & .09 & $.30 * * *$ \\
\hline Reconsideration (A) & 0.29 & .05 & $.32 * * *$ & 0.42 & .06 & $.38 * * *$ & 0.21 & .07 & $.19 * *$ & 0.35 & .06 & $.36^{* * *}$ \\
\hline Reconsideration $(\mathrm{F})$ & 0.33 & .06 & $.33 * * *$ & 0.25 & .07 & $.24 * * *$ & 0.32 & .07 & $.30 * * *$ & 0.28 & .07 & $.28 * * *$ \\
\hline \multicolumn{13}{|l|}{ T1 Associations } \\
\hline Reconsideration (A) - Balanced relatedness & -1.82 & .50 & $-.21 * * *$ & & & & & & & & & \\
\hline Reconsideration (A) - Reconsideration $(\mathrm{F})$ & 1.04 & .44 & $.13 *$ & & & & & & & & & \\
\hline Balanced relatedness - Reconsideration $(\mathrm{F})$ & -0.56 & .40 & -.07 & & & & & & & & & \\
\hline \multicolumn{13}{|l|}{ Cross-lagged effects } \\
\hline Balanced relatedness $\rightarrow$ Reconsideration (A) & -0.05 & .03 & $-.06 *$ & -0.05 & .03 & $-.06 *$ & -0.05 & .03 & $-.05 *$ & -0.05 & .03 & $-.06 *$ \\
\hline Reconsideration $(\mathrm{A}) \rightarrow$ Balanced relatedness & -0.05 & .03 & -.05 & -0.05 & .03 & -.04 & -0.05 & .03 & -.04 & -0.05 & .03 & -.04 \\
\hline Reconsideration (F) $\rightarrow$ Reconsideration (A) & 0.02 & .03 & .03 & 0.02 & .03 & .02 & 0.02 & .03 & .02 & 0.02 & .03 & .02 \\
\hline \multirow[t]{3}{*}{ Reconsideration $(\mathrm{A}) \rightarrow$ Reconsideration (F) } & 0.01 & .03 & .01 & 0.01 & .03 & .01 & 0.01 & .03 & .01 & 0.01 & .03 & .01 \\
\hline & \multicolumn{3}{|c|}{$\mathrm{T} 2$} & \multicolumn{3}{|c|}{$\mathrm{T} 3$} & \multicolumn{3}{|c|}{$\mathrm{T} 4$} & \multicolumn{3}{|c|}{ T5 } \\
\hline & $B$ & $S E$ & $\beta$ & $B$ & $S E$ & $\beta$ & $B$ & $S E$ & $\beta$ & $B$ & $S E$ & $\beta$ \\
\hline \multicolumn{13}{|l|}{ Correlated residuals } \\
\hline Reconsideration (A) - Balanced relatedness & -0.58 & .22 & $-.09 * *$ & -0.58 & .22 & $-.09 * *$ & -0.58 & .22 & $-.07 * *$ & -0.58 & .22 & $-.07 * *$ \\
\hline Reconsideration (A) - Reconsideration (F) & 0.37 & .20 & .06 & 0.37 & .20 & .05 & 0.37 & .20 & .05 & 0.37 & .20 & .05 \\
\hline Balanced relatedness - Reconsideration $(\mathrm{F})$ & -0.17 & .22 & -.02 & -0.17 & .22 & -.02 & -0.17 & .22 & -.02 & -0.17 & .22 & -.02 \\
\hline
\end{tabular}

Note. $(\mathrm{A})=$ of the target adolescents; $(\mathrm{F})=$ of the best friends. 2-year stability paths were estimated but were omitted from this table.

$* p<.05 . * * p<.01 . * * * p<.001$. 